\title{
Container Gardens for Outdoor Spaces ${ }^{1}$
}

\section{Gary W. Knox ${ }^{2}$}

Container gardening is one of the most popular gardening trends today. Mixed plantings in large containers create focal points by combining decorative containers, dramatic plant forms and colorful flowers and foliage at entrances and on decks and patios (Figure 1). Container gardening literally elevates plants, bringing them closer to eye level and making them more prominent than a similar grouping of plants at ground level. In addition, the container itself can be very decorative and provide architectural interest.

\section{Design and Use}

Today, container gardening generally refers to large containers planted with a mixture of plants. Current trends combine various annuals and perennials with tropical plants, seasonal plants and even woody plants. Creating a beautiful container garden utilizes - on a smaller scale - all the same elements of design used in creating beautiful landscapes: color, form, line, proportion, and texture (Circular 536, Basic Principles of Landscape Design, http://edis.ifas.ufl.edu/MG086).

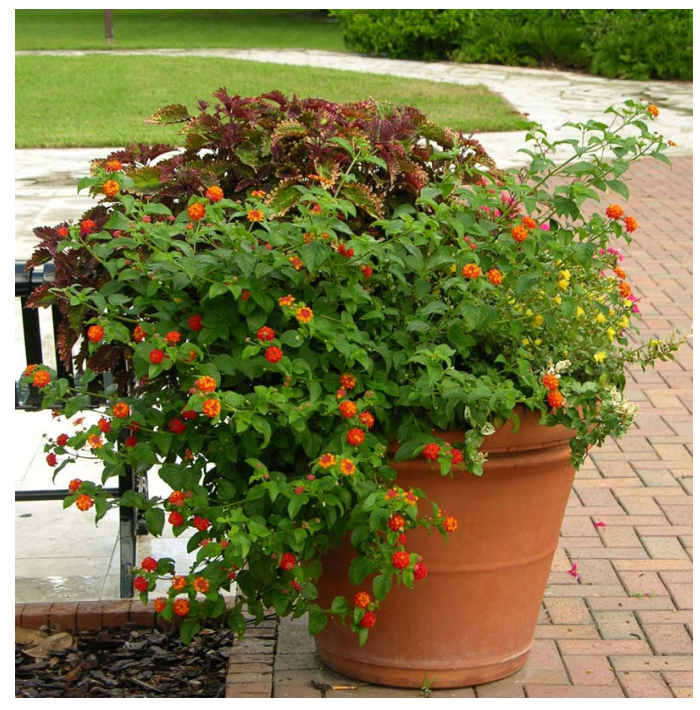

Figure 1. A large container of mixed annuals and perennials adds color to this patio.

\section{Designs}

Here are some examples of tried-and-true designs that create eye-pleasing container gardens:

- Determine which side of the container is the primary view, or "front." Place several plants in the container so that tallest plants are in the back and shortest plants are at the front edge of the pot (Figure 2). Repeat some of the same plants if the container is large enough. This helps create unity and continuity.

1. This document is ENH1095, one of a series of the Environmental Horticulture Department, Florida Cooperative Extension Service, Institute of Food and Agricultural Sciences, University of Florida. Original publication date February, 2008. Visit the EDIS Web Site at http://edis.ifas.ufl.edu.

2. Gary W. Knox, Associate Professor, Department of Environmental Horticulture, Cooperative Extension Service, Institute of Food and Agricultural Sciences, University of Florida, Gainesville, 32611.

The Institute of Food and Agricultural Sciences (IFAS) is an Equal Opportunity Institution authorized to provide research, educational information and other services only to individuals and institutions that function with non-discrimination with respect to race, creed, color, religion, age, disability, sex, sexual orientation, marital status, national origin, political opinions or affiliations. U.S. Department of Agriculture, Cooperative Extension Service, University of Florida, IFAS, Florida A. \& M. University Cooperative Extension Program, and Boards of County Commissioners Cooperating. Larry Arrington, Dean 


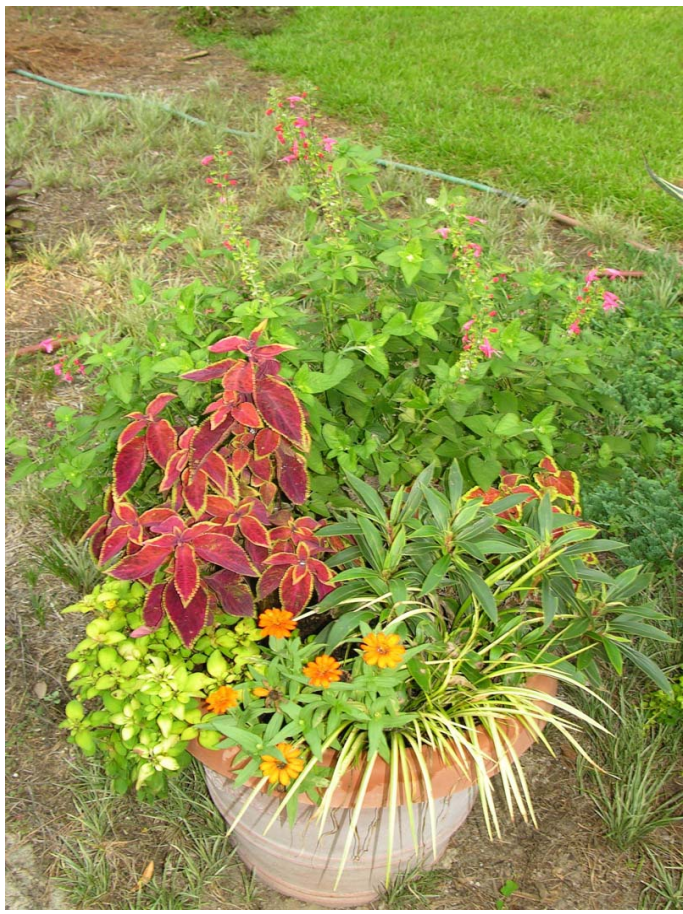

Figure 2. This simple design uses a mix of tall plants placed in the back and short plants positioned along the front edge of the container.

- Use a specimen plant in the center of a pot as an "anchor" around which colorful annuals and perennials can be planted (Figure 3). The specimen plant provides a background against which the annuals and perennials display their color. The specimen plant provides the permanent component in the container. Changing the annuals and perennials seasonally or as needed keeps the plant composition looking "fresh."

- With large containers, partially bury empty containers around the specimen plant to allow quick and easy changes of seasonal color by "dropping in" pots of annuals.

- Another sure-fire arrangement uses a trio of an upright plant, a mounding plant (or plants), and a trailing or weeping plant (Figure 4). The mounding plant forms the overall mass of the planting while the upright plant catches the eye and the trailing or weeping plant softens the container edge and adds interest.

- For a classic look, use a single specimen plant (Figure 5). This style highlights that plant and creates an air of simple elegance. However, that single plant has to be top-notch in appearance and vigor or the container garden will appear "tired." Choices for the single specimen plant might be a large succulent, palm, cycad or ornamental grass.

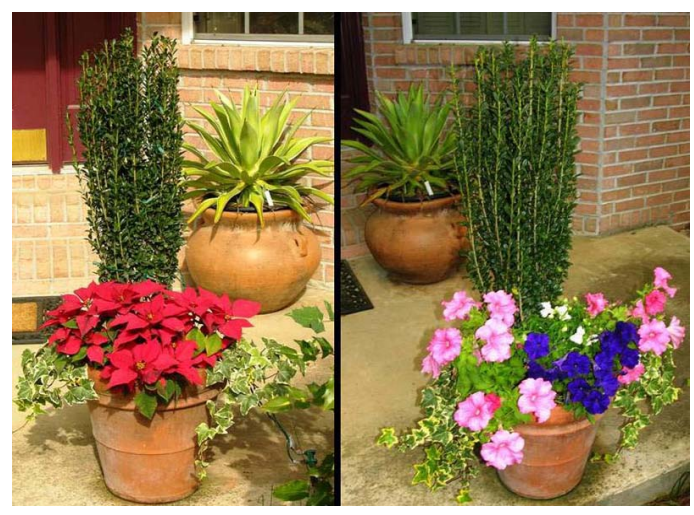

Figure 3. This container features an evergreen as the "anchor" plant with poinsettias used for winter color and petunias for spring color.

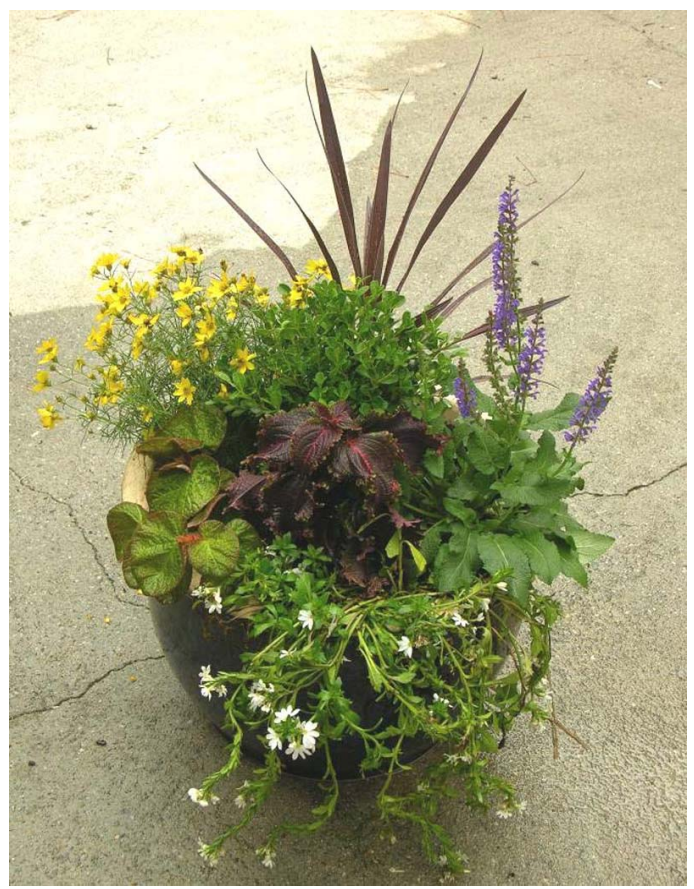

Figure 4. A grass-like plant acts as a vertical accent and a trailing annual adds interest to the mix of mounding annuals and perennials.

\section{Plants for Visual Impact}

Certain plants or plant combinations add extra "zing" to container gardens:

- Large-leaved plants like palms and "tropicals" provide lots of interest because of their coarse, bold textures and odd shapes. 
- Ornamental grasses, including bamboo, add an extra dimension of movement because their foliage sways in the breeze (Figure 6).

- "Hot" color combinations also draw the eye and add interest. Combinations that attract attention include:

- Mixes of burgundy/purple-leaved plants with silver-, yellow-, or chartreuse-leaved plants.

- Yellow flowers mixed with red or orange flowers.

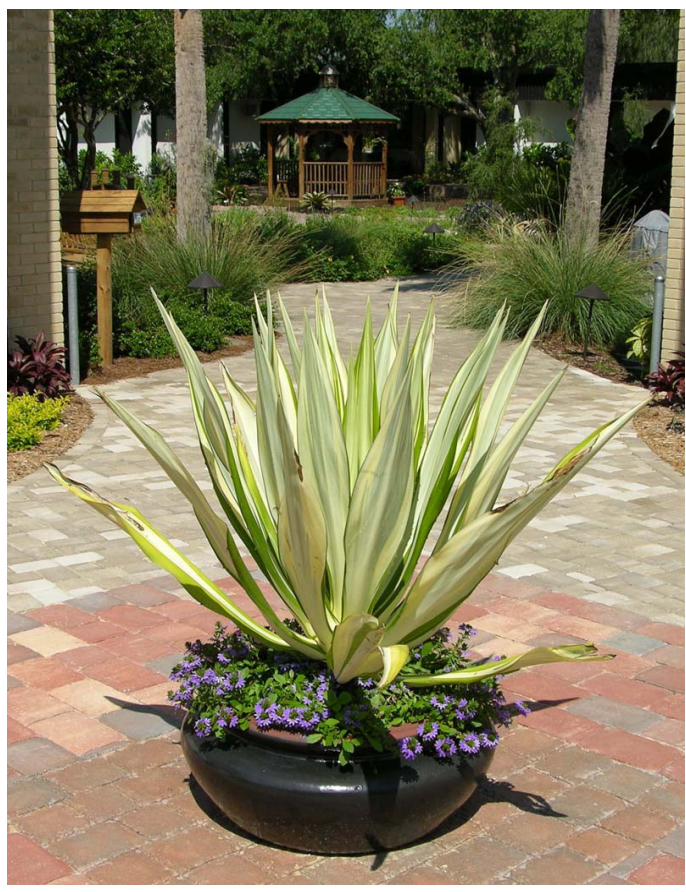

Figure 5. A single succulent in a container creates a dramatic focal point at the entrance to this garden.

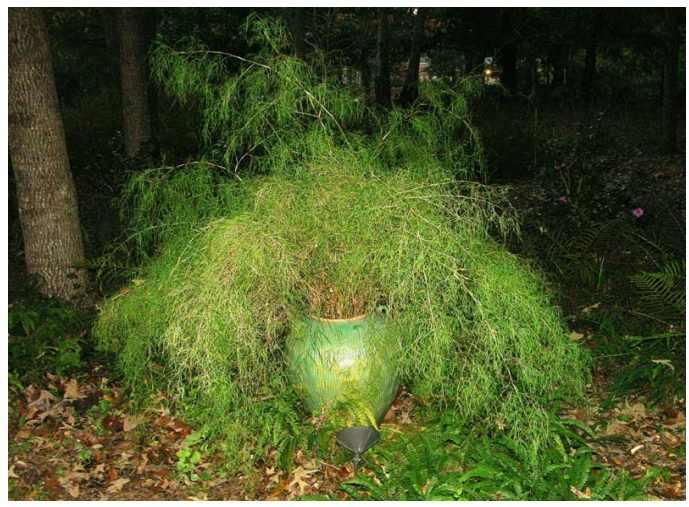

Figure 6. This fine-textured grass moves in the breeze, adding extra drama to the container garden.

\section{Other Tips}

Here are some additional tips for using container gardens and increasing their visual impact:

- Think big! The latest trend is to use large containers, and the larger, the better. For greatest impact, the container needs size, color or dramatic shape.

- Incorporate small trellises, plant supports or small decorative objects to add height and drama to a container garden. However, be careful not to use too many or too large non-plant components or these objects will dominate the container garden.

- Sometimes you can increase the dramatic effect of a small container by simply placing it on a pedestal or otherwise elevating the container to bring it closer to eye level (Figure 7).

- Don't stop with just one! Groupings of containers create impressive displays. However, don't use a hodge-podge of containers and plants - be sure to unify the grouping by using one or more of the following:

- Same-shaped container in different sizes

- Same type of container (i.e., concrete, glazed pottery, fiberglass, etc.)

- Same color of container

- Same dominant plant form in all containers (i.e., spiky plants, or trailing plants)

- Same accent color in all containers (i.e., burgundy foliage, white variegated foliage or orange flowers)

- Shady sites need brighter colors for impact. Colors under shade often appear more muted than in sunlight.

- Use containers in garden beds to define or divide space, accent a garden border, or add color to a planting during its off-season. Container gardens can be permanent components of the garden, or temporary accents used when needed. 
- Take advantage of the portability that containers allow

- Rearranging containers creates a fresh composition and doesn't cost any more than a bit of effort.

- It may be necessary to relocate containers with the season, i.e., moving sun-loving plants out of shadows to sunnier environs as the days shorten, or moving containers with tender plants to protected corners during cold weather.

- Finally, remove "tired" container gardens. Shift them to less visible areas when plants need a little "R \& R" to recover and achieve their former glory.

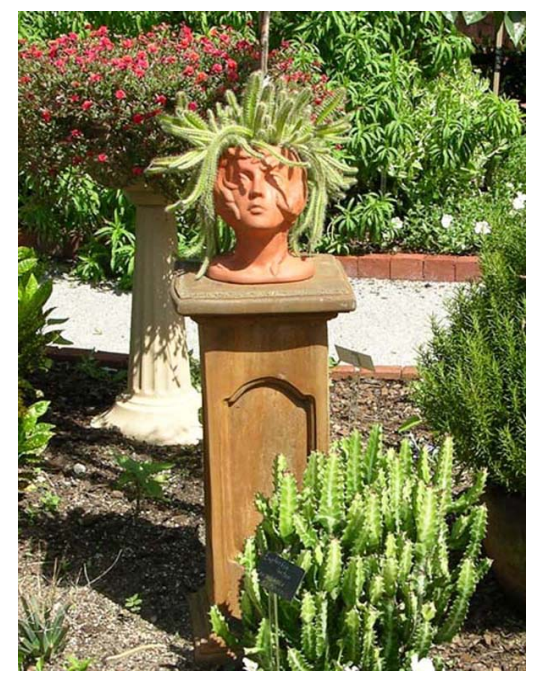

Figure 7. Achieve greater impact with a small container by placing it on a pedestal.

\section{Plant Selection}

As with plants in the landscape, use the rule of "right plant, right place" when selecting plants for containers. If more than one plant will be used, make sure all of them require similar conditions. Primary considerations are the amount of light, water, and fertilizer. Mismatched plants usually result in some plants outperforming others in terms of growth or health.

Another consideration is matching plant growth rate and ultimate plant size to the size of the container. Plants that grow large or grow quickly will need larger containers to accommodate their root systems and top growth. Containers that are too small may stunt plant growth and reduce plant vigor, resulting in sickly plants.

Container gardens with several plants generally should be start with small plants at potting. This allows plants to grow together to develop an attractive cohesive appearance. Containers planted for instant impact usually look like a collection of individual plants and not a unified container garden. In addition, containers planted initially with larger plants become overgrown quickly.

Plant type affects maintenance level. Annuals are replaced seasonally. Perennials require regular grooming and replacement as needed. Most trees and shrubs eventually will outgrow containers, or have shorter lifespans. Perennials are the best companion plants for a small tree or shrub in a container. After a year or two, tree and shrub root systems will dominate the container and make it difficult to replant annuals seasonally.

Current publications from UF/IFAS Extension are good references for lists of plants. These include:

- Circular 569, Annual Flowers for Florida, http://edis.ifas.ufl.edu/MG018

- Circular 1134, Bedding Plants: Selection, Establishment and Maintenance, http://edis.ifas.ufl.edu/MG319

- ENH 976, Considerations for Selection and Use of Ornamental Grasses, http://edis.ifas.ufl.edu/EP233

Use the EDIS "search" feature to find other plants: http://edis.ifas.ufl.edu.

\section{Planting a Container Garden}

\section{Container Types}

A wide variety of container types, sizes, shapes, and materials are available. Some decorative containers have a removable inner pot (Figure 8). Extra inner pots allow you to have "back-up" container plantings. You can easily exchange planting pots whenever the display container garden looks "tired" without moving the outer decorative pot or replanting and 
waiting for the new plant to mature. An inner pot is vital to the long-term durability and appearance of wood, wicker and other perishable container types.

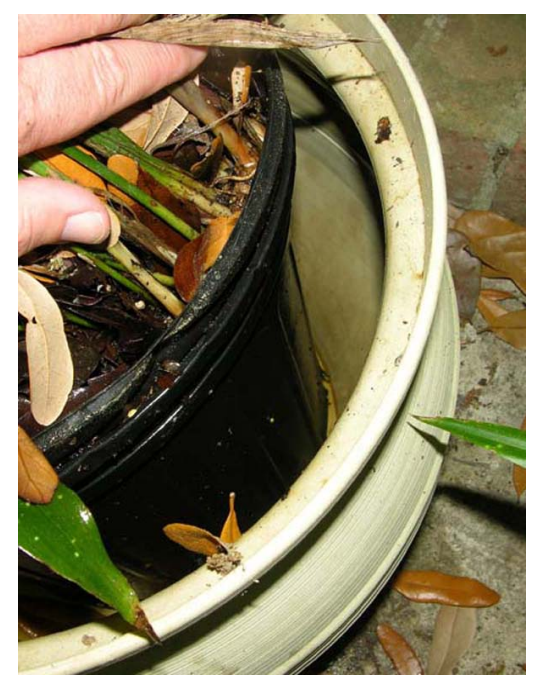

Figure 8. An inner container allows easy removal and replacement when plants fade.

The most important aspect of a container is drainage. Make sure the container has drain holes or otherwise provides for soil drainage. Sometimes drain holes can be drilled, but this depends on the container material and the skill and tools of the gardener.

Other considerations pertain to size, weight, and shape. Any object that holds potting soil (and provides drainage) is a possible container, but the smaller the container, the more often it will need to be watered. Containers should be heavy enough not to topple over in winds, especially when planted with tall, top-heavy plants. One final consideration is container shape: shallow containers ultimately are harder to maintain because they limit plant rooting depth and usually require more frequent watering.

\section{Potting Soil}

A good potting soil combines materials that absorb and retain moisture (such as peat moss) with materials that allow water to drain (such as perlite). Lightweight potting soils reduce the overall weight of the container. Avoid fine-textured or heavy potting soils since these usually hold too much water, reducing root aeration and potentially stressing plants.

Deep or large containers require exceptionally large amounts of potting soil. Reduce the amount of potting soil needed by placing light-weight "filler," such as Styrofoam ${ }^{\mathrm{TM}}$, packing peanuts, lava rock, empty plastic bottles or commercially available plastic meshes manufactured for this purpose in the bottom of a large container. These materials will not affect root growth of most plants but will make the container lighter in weight and easier to move.

\section{Planting}

Procedures for planting container gardens are similar to those for planting in the landscape (Circular 858, Selecting and Planting Trees and Shrubs, http://edis.ifas.ufl.edu/MG077). Container planting involves partially filling the container with potting soil and placing plants to determine the desired arrangement. Continue filling the container with potting soil and adjust plant rootball depth as needed so that the top-most root of each plant is even with the surface of the potting soil. The final level of potting soil should be 1 to 2 inches below the rim of the container to allow for watering. Mulch sometimes is used when plant growth will not cover the potting soil surface. Mulch typically is not used in densely-planted containers because of close plant spacing and growth that usually covers the potting soil surface.

Plant large container gardens in-place at your site selection since they can be quite heavy when completed. Alternatively, be prepared to use a hand truck, dolly, powered lift truck, or "muscle-power" to position the container. On hard surfaces, place containers on plant stands with castors that allow the container garden to move easily. Some containers can be purchased with built-in castors.

\section{Drainage Water}

Lastly, provide somewhere for drainage water to go. Water that drains onto a patio, sidewalk or other surface may be a safety hazard as well as unsightly (Figure 9). 
Place saucers under containers to collect drainage water or make sure water unobtrusively flows to mulched or landscaped areas where it can be absorbed. A decorative outer container without drainage holes also performs as a saucer or reservoir to capture drainage water. Some large containers include tanks to store drainage water until it can be removed or re-absorbed by the potting soil. Other large containers may have elaborate drainage pipes to convey excess water to landscaped areas or stormwater systems.

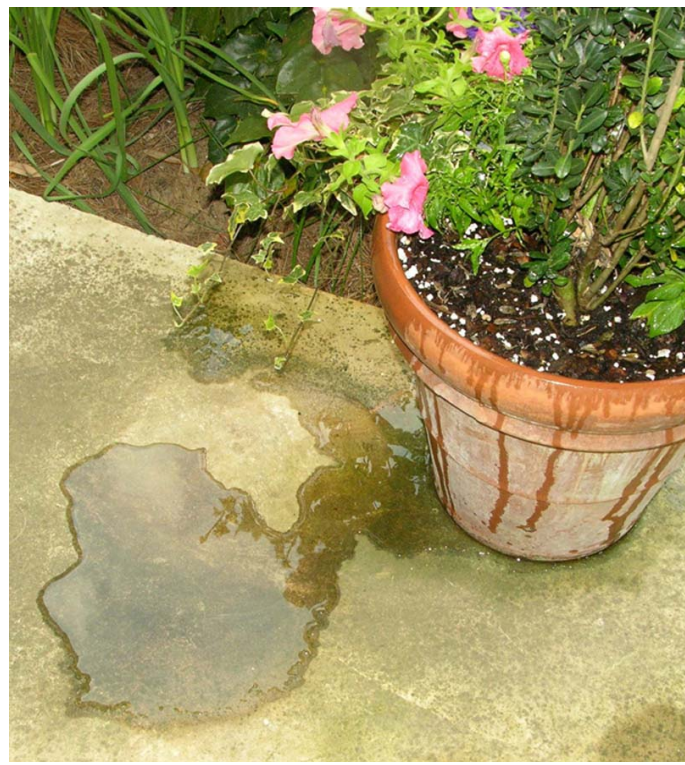

Figure 9. Drainage water can be a hazard as well as unsightly.

\section{Maintenance}

Container gardens require more intensive maintenance than plantings in ground beds. Because container plants are prominently displayed, they need to be actively growing or flowering and in top shape all the time.

\section{Irrigation}

Irrigation is absolutely critical. The limited volume of potting soil in a container limits the amount of moisture that plants can obtain. Rainfall can help supply moisture if the container is not under a roof or tree. However, hot or dry weather can quickly deplete soil moisture. Water frequently to replenish soil moisture, usually at least three times a week. If hand-watering, use a hose-breaker or watering can that applies water in slow streams so as not to disturb potting soil or shallow roots. Watering in early morning keeps plants perky all day. Remember that plant water requirements will change with season, rainfall, stage of growth, and plant size.

To avoid becoming a "slave" to watering, install a drip or micro-sprayer irrigation system that simultaneously and gently waters all plants (Figure 10). Automate the system by using a battery-operated timer. Components of drip or micro-sprayer irrigation systems generally are easier to install prior to and during planting.

Alternatively, stretch intervals between waterings by using plants that don't wilt easily such as succulents, palms, cycads, grasses, cacti and other similar plants. In contrast to drought tolerant plants, bog and water gardens in containers also may allow longer intervals between waterings.

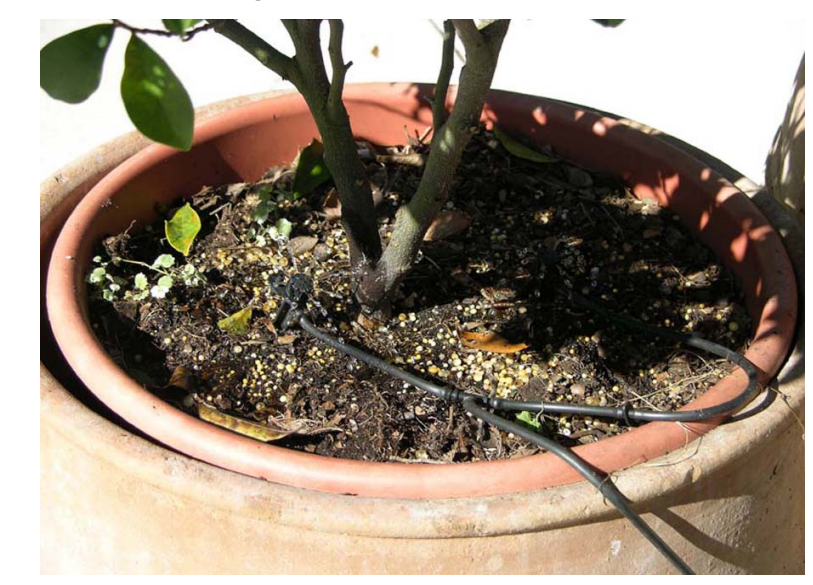

Figure 10. A micro-sprayer irrigation system makes watering easier.

\section{Fertilization}

Soluble fertilizers quickly leach from containers because of the frequent watering required. To maintain fertility levels, use a slow-release fertilizer that will provide steady release of nutrients throughout the decorative lifespan of plants in the container.

\section{Pest Management}

Stressed plants are more susceptible to pests. Plants in container gardens are easily stressed by too much or too little water, crowding, salt damage from excess 
fertilizer, nutritional imbalances, or

exposure to heat and cold.

At the other extreme, optimum watering and excess fertilizer may result in succulent plant growth susceptible to pests such as aphids and some leaf spots. Scouting for pests is an important component of regular container garden maintenance. Since most container gardens are located in public areas, patios and entranceways where people are in close contact with these plants, use the least toxic methods of pest control possible when necessary.

\section{Plant "Grooming"}

Routinely deadhead plants to remove unsightly dead flowers and encourage new blooms. Similarly, pinch back or tip-prune plants regularly to keep plant growth in check, stimulate fresh growth, encourage branching, and keep the plant compact or bushy. Periodically remove containers from public view and move them to a protected location for replanting or to allow plants to recover.

\section{Container Gardening Today}

Container gardening has evolved far beyond the simple clay pots of yesteryear. Today's containers come in an array of materials, shapes, sizes and styles suited to almost any location or use. A broad range of plants are amenable to container culture and are widely available in many sizes. Modern potting soils, fertilizers and irrigation systems allow container plants to thrive while easing maintenance needs. Finally, current design styles allow imaginative use of plants and containers to create focal points, frame views, and add interest to entrances, decks and patios. Never before has container gardening been as easy, or as enjoyable! 